\title{
Empreendedorismo como ideologia: análise do enfoque da revista Exame em dez anos de publicação (1990-99)*
}

\author{
Vanessa Tavares Dias ${ }^{l}$ \\ Ursula Wetzel
}

Universidade Federal do Rio de Janeiro

A crise estrutural do capitalismo, que teve início em fins dos anos 60 do último século, provocou, dentre outros fatores, a escassez de emprego em todo o país. Ao mesmo tempo em que ocorria a precarização das relações de trabalho, uma nova ideologia formulada e difundida por diversas agências da sociedade civil estabelecia uma nova "ética" do trabalho sob a égide do "empreendedorismo". A tarefa deste artigo é compreender como a revista Exame aborda esta temática e qual o seu conteúdo ideológico particular. Foram analisados artigos que tratam o tema "empreendedorismo" de todas as edições da revista publicadas entre 1990 e 1999 . Os resultados obtidos indicam que as narrativas usam o termo em análise de forma elástica, adaptável ao propósito de cada matéria; todavia tendem a convergir no sentido de valorização do "empoderamento"2 individual e do empresariamento geral, este como condição imperativa para a adaptação aos "novos tempos".
The structural crisis of capitalism, starting at the end of the 60's of the last century, has led, among other things, to a reduction in employment levels in Brazil. In parallel to a process of precarization of work relations, a new ideology formulated and disseminated by several agents in the civil society presented a new work "ethics" under the scope of "entrepreneurship". This article examines how the Brazilian business maganize Exame approaches this phenomenon and what is its specific ideological content. Articles on "entrepreneurship" in all issues between 1990 and 1999 were analyzed. Results show that the narratives use the word in several different meanings, depending on the purpose of the the piece. However, they tend to converge to the sense of giving value to individual empowerment and to widespread entrepreneurship, which is seen as an imperative for an adaptation to the "new times".

\footnotetext{
*Entrepreneurship as ideology: an analysis of the focus of a brazilian business magazine over a tenyear period (1990-1999)

${ }^{1}$ Endereço para correspondências: Rua Machado de Assis, 30, apt. 401, Flamengo, Rio de Janeiro, RJ, 22220-060 (vdias@iuperj.br).

${ }^{2} \mathrm{O}$ termo "empoderamento", tradução literal do inglês empowerment, tem sido utilizado pela literatura científico-social brasileira, em geral, como sinônimo para desenvolvimento ou aquisição de poder por indivíduos, movimentos sociais, grupos ou comunidades locais no novo contexto das relaçōes de força que atuam na sociedade. Desta forma, pode estar se referindo a mudanças estruturais e sua influência sobre a capacidade dos sujeitos individuais ou coletivos de atuarem, intervirem ou mudarem efetivamente as políticas públicas e a ordem sócio-econômica vigente.
} 
Palavras-chave: Empreendedorismo

- Ideologia - Mídia de negócios
Keywords: Entrepreneurship - Ideology - Business media

\section{Introdução}

U

m dos assuntos mais recorrentes discutidos atualmente dentro do campo das ciências sociais "aplicadas" e "não aplicadas" são as transformações que incidiram nas relações de produção iniciadas no último quartel do século XX. Múltiplas reflexões assinalam a falência do modelo fordista e a ascensão de outros mecanismos produtivos pós-fordistas, pós tayloristas ou toyotista motivadores da reestruturação das relações sociais no atual contexto do capital. Outras análises apontam para a remodelação do taylorismo que teria sofrido adaptações em acordo com as exigências das novas condições tecnológicas do mundo globalizado. Em ambos os casos, porém, os analistas admitem a tese que aponta para a emergência de um novo padrão de acumulação que passa a instar a fabricação por encomenda, com diminuição de estoques, redução da necessidade de contratação de número extenso de trabalhadores e aumento significativo de contratos de trabalho estabelecidos à margem da lei.

No Brasil, o governo de Fernando Collor de Mello (1990 - 92) deu início e o de Fernando Henrique Cardoso (1995 - 2002) arrematou o projeto econômico de cunho neoliberal que incluía novas formas de organização da produção. No âmbito privado, observou-se a desintegração de algumas empresas, surgimento de grandes corporações pelo processo de fusão, compra de competidores por multinacionais e desenvolvimento de franquias internacionais. Na esfera estatal, uma reordenação de estruturas e funções teve como propósito sustentar as novas formas de acumulação: modificação da legislação trabalhista, com a diminuição de direitos, privatização de empresas públicas, terceirização de serviços do próprio Estado, programas de demissão voluntária e precarização da situação salarial do servidor público. Este conjunto de medidas ocasionou, dentre outros aspectos, multiplicação dos índices de desemprego em todo o país, desaparecimento de determinadas carreiras e de empregos estáveis, aumento do trabalho informal e autônomo e surgimento de subcontratados (CARDOSO, 2003; ANTUNES, 2003).

No entanto, se grande parte dos estudiosos do assunto, em aquiescência, reporta as últimas décadas como marcadas por grave processo de degradação das condições de trabalho e aumento do desemprego estrutural (ANTUNES, 2003 \& 2001; CARDOSO, 2003; MACHADO DA SILVA, 2001; NEVES, 2000; HOBSBAWN, 1995), outra perspectiva, malgrado confirme a atual condição vulnerável do trabalhador, considera que nunca houve na história do capitalismo período mais propício para o aprimoramento das potencialidades criativas dos indivíduos. As análises favoráveis à conjuntura recente, 
protagonizadas em geral por administradores (DIAS, 2008), e inspiradas na maioria das vezes numa releitura da tipologia do sujeito empreendedor schumpeteriano (CAMPOS, 2003), partem do pressuposto de que a ausência de empregos configurar-se-ia em fenômeno capaz de impulsionar o indivíduo a inventar novas possibilidades de sobrevivência, ao mesmo tempo em que conseguiria, com idéias inventivas, alavancar a economia de um país.

Paralelamente ao debate acadêmico, uma panacéia relativa aos benefícios advindos do "empreendedorismo" tornou-se tema central difundido por diferentes agências, tais como meios de comunicação, SEBRAE, organizações não-governamentais, universidades e escolas públicas e privadas, além dos próprios governos. Não obstante as diversas formas de enunciar a proficuidade da "nova economia", agentes exaltam a iniciativa particular do indivíduo em abrir um negócio ou dedicarse a qualquer atividade autônoma que lhe permita tornar-se "patrão de si mesmo". Deste prisma, o "empreendedorismo" significaria um recurso moderno e mais adequado para os indivíduos se inserirem no mundo do trabalho em transformação.

No conjunto das agências citadas, a mídia impressa ocupa atualmente papel estratégico no que tange à organização e o controle social (JAMESON, 1984) e, por conseguinte, parece desempenhar papel central na construção e difusão da idéia do "empreendedorismo" (FONSECA, 2003b; CAMPOS, 2003; GRÜN, 2000; SILVA FILHO, 1998).

Ante ao exposto e partindo do pressuposto de que esta noção ganha contornos particulares de acordo com a natureza da fonte e o público para o qual está sendo destinada a mensagem, a tarefa deste artigo é, primeiramente, compreender como uma mídia de negócios de grande circulação no Brasil aborda esta temática. Em segundo lugar, compreender o seu conteúdo ideológico. Neste sentido, entendemos ideologia como sendo um conjunto de idéias que têm a capacidade de moldar necessidades, desejos e comportamentos dos receptores, mas que guarda, de maneira significativa, identificação com as necessidades e os desejos que as pessoas já têm. Ou seja, contrariamente à perspectiva que entende ideologia como uma imposição de interesses unilaterais, ela encerra, por um lado, certa substância real, na medida em que consegue fazer com que os indivíduos se identifiquem com princípios e valores; mas, por outro, apresenta certa substância falsa, no sentido de não revelar as contradições e incoerências dessas próprias idéias (EAGLETON, 1997).

Para a análise, elegemos a revista Exame como objeto e campo de estudo, mais precisamente, matérias publicadas entre 1990 e 1999. Após esta introdução, buscaremos apresentar a relação estabelecida entre a nova organização do mundo do trabalho e a emergência da ordem ideológica regulada pelas idéias associadas ao "empreendedorismo". Também será abordada a importância da mídia como propagadora central de certa cultura de natureza corporativa, na qual se encontram os vários sentidos dados ao termo em questão. 
Em seguida, buscaremos explicitar as etapas de pesquisa, evidenciando a escolha e o recorte do objeto, assim como os instrumentos teóricos escolhidos para investigação da fonte. Posteriormente, apresentaremos, de forma sintética, a análise de 86 reportagens selecionadas. Por fim, buscaremos estabelecer algumas conclusões possíveis.

\section{Toyotismo, Pequena Empresa, Informalidade e Empreendedorismo}

Uma das respostas dadas pelo capital à última grande crise da acumulação, como dito anteriormente, foi a adoção de novos mecanismos produtivos. O modelo de administração toyotista, que acabou influenciando quase todo o mundo capitalista, não significou a adoção de uma forma de produção em si, mas uma nova organização da produção capitalista relacionada à grande indústria. Assim, além de não substituir integralmente o fordismo/taylorismo, o toyotismo, tendeu a mesclar-se com outras formas de racionalização que dão maior eficácia à lógica da flexibilidade da produção (BERNARDO, 2009; ALVES, 2007, ANTUNES, 1995).

Como diversos analistas têm apontado, as características mais gerais do toyotismo são, primeiramente, a introdução no core das corporações industriais de uma série de inovações tecnológicas associadas a formas de organização da força de trabalho e demandas relativas a novas qualificações e à mulifuncionalidade dos funcionários. Contudo, como aponta Alves (2002, p.79), o toyotismo sistêmico se disseminou para "a borda periférica do sistema industrial e de serviços, através das suas redes de subcontratação, constituídas através de médias e pequenas empresas". Logo, com o toyotismo, a empresa "enxuta", passa a demandar a multiplicação de empresas de menor porte, voltadas a atividades diversificadas, para as quais foram delegadas funções antes abrangidas pela grande indústria, estabelecendo-se, assim, uma relação de dependência das pequenas empresas em relação à necessidade das grandes.

A partir desse novo contexto, o debate público passa a apresentar as pequenas unidades produtivas a partir de sua capacidade de inovar e de gerar empregos, as colocando como chave para o desenvolvimento econômico de um país. Adeptos desta perspectiva passam a defender a figura e o ethos particular do "empreendedor", neste caso identificado com o pequeno empresário, como fundamentais para a sobrevivência de seus empreendimentos e do sucesso de suas atividades (CAMPOS, 2003).

Ao mesmo tempo em que se multiplicava este tipo de empresa, os dispensados da indústria passaram a ser empurrados para ocupações informais, terceirizadas ou autônomas. Sendo assim, pequenos empresários, cujo status social difere significativamente do empresário industrial, juntamente 
com trabalhadores assalariados e não assalariados irão compor a nova face da classe trabalhadora, mais complexificada, fragmentada e heterogênea em relação àquela encontrada em passado recente (ANTUNES, 1995). Além disso, o avanço da tecnologia, as atividades vinculadas ao setor de serviços e a ênfase na informação passaram a formar novo contexto para as relações de trabalho, que parece deslocar a experiência da atividade repetitiva dos operários no chão de fábrica para outras experiências laborativas, também distintas da racionalização conexa ao trabalho industrial.

Estas mudanças levaram à formulação de um discurso acadêmico por vezes romantizado, baseado na idéia de que a relação entre capital e trabalho teria se tornado mais humanista (SILVA, 2008). Por este motivo, diversos autores têm chamado a atenção para o fato de que as novas formas de organização da produção não são contraditórias à dinâmica capitalista, visto que não transformaram o processo de exploração (ALVES, 2007; ANTUNES, 1995; HARVEY, 1992). Pelo contrário, através da reestruturação produtiva, e a conseqüente proliferação de outras atividades laborativas "exteriores" à indústria, o capital conseguiu recompor a sua taxa de lucro e associar mais-valia absoluta e relativa (ORGANISTA, 2006), mantendo-se sempre em situação ascendente.

As mudanças no âmbito da produção e das relações de trabalho estimularam o campo das ciências sociais a repensar a própria categoria trabalho, considerada, até então, desde os fundadores da sociologia, chave para a compreensão da dinâmica social, fenômeno que daria respostas a questões relativas à integração, conflitos, estruturas sociais e futuro das sociedades (OFFE, 1995).

Claus Offe, Jürgen Habermas e André Gorz, por exemplo, apresentaram diferentes teses cujo objetivo final seria demonstrar que o trabalho e o capital teriam sido substituídos na contemporaneidade pela informação e pelo conhecimento, sendo este a origem do valor (ORGANICISTA, 2006). Offe (1995), em particular, argumenta que a racionalidade técnica do período fordista teria sido substituída pela capacidade de interação, consciência da responsabilidade, empatia e experiência pela prática. E a repressão à racionalidade 'substantiva' na esfera produtiva (transformação do trabalhador em mercadoria) teria cedido lugar à racionalidade de um trabalho qualificado em serviços, mediador e regulador, ordenador e normalizante, que garantiria institucionalmente a existência social.

Por outro lado, os argumentos que afirmam a perda de centralidade da categoria são criticados por um conjunto de analistas que percebem nesta perspectiva o eclipse do revigoramento das formas de exploração e de acumulação no capitalismo contemporâneo. Antunes (1995), por exemplo, ao considerar o trabalho fenômeno ontológico, argumenta que as análises que rejeitam a sua centralidade no capitalismo negam-se a observá-lo em perspectiva dialética, também como trabalho abstrato criador de valores de troca. E, deste prisma, 
ele continua alienado e eficiente para o processo de acumulação. Alves (2007, p. 246), da mesma forma, observa que o toyotismo nada mais é do que um estágio superior no que tange à racionalidade fordista-taylorista e, portanto, trata-se de um avanço nas formas de exploração capitalista, estando o trabalhador "imerso numa nova forma de estranhamento e objetivações fetichistas", cuja determinação seria a chamada "empregabilidade" - demanda por certos conhecimentos, habilidades cognitivas e comportamentais dos trabalhadores, assim como por seu envolvimento participativo.

De acordo com Alves (2007) e Campos (2003), um dos aspectos que caracteriza o toyotismo e que faz parte do seu aparato ideológico é justamente a contradição estabelecida entre a exclusão do pleno emprego e a promessa de que a chamada "empregabilidade" integraria ou perpetuaria a condição do trabalhador empregado. Em outras palavras, o fato do trabalhador aprimorar todo o tempo os seus conhecimentos com o objetivo de manter o vínculo formal com a corporação não sucede, na prática, em garantia de que não será demitido a qualquer tempo. Desta forma, ainda para Alves, a idéia da "empregabilidade" tem como propósito realizar uma subsunção formal-intelectual do trabalho num novo contexto das relações sociais.

Podemos conjeturar que se o discurso voltado para a "empregabilidade" incide sobre trabalhadores diretamente vinculados ao cotidiano da grande indústria, ele perde grande parte de sua eficácia diante do número extenso de trabalhadores fora do mercado formal. É aí que a noção de "empreendedorismo" - originalmente ligada à atividade e à figura do pequeno empresário consegue cingir tipos distintos de trabalhadores, envolvendo, desta forma, toda a sociedade na atividade produtiva. Os agentes e agências da sociedade civil que difundem esta idéia irão articular de forma pouco lógica a figura do pequeno empresário, do "intraempreendedor" (empregado que detém iniciativa para inovar dentro da corporação) e do trabalhador autônomo ou informal, demandando deles, unanimemente, as mesmas habilidades.

Todo momento de reestruturação do capital precisa ser acompanhado por uma reforma moral e intelectual do complexo social (GRAMSCI, 2001). O toyotismo, desta feita, representaria "uma nova ideologia orgânica da produção capitalista sob a mundialização do capital" (ALVES, 2007, p.60), cenário material e ideal a partir do qual serão produzidos novos valores e novos sentidos para as relações sociais. Todavia, o discurso ideológico, que tem como objetivo adequar os sujeitos às necessidades atuais da produção, precisa apresentar alguma inovação em relação ao passado para ser eficaz. É por este motivo que velhos fenômenos passam a ser abordados a partir de significados renovados. $\mathrm{O}$ trabalho informal, por exemplo, visto no passado como atividade degradante, tem sido tratado correntemente como sinônimo de "empreendedorismo", isto é, como atividade laborativa realizada por sujeitos criativos e corajosos, 
que não se contentam com funções pouco desafiadoras (BERNARDO, 2009, CAMPOS, 2003). Esta inversão interpretativa do informal associa-se à determinada ética do trabalho relacionada à rejeição da "rotina" e à valorização do risco, persuadindo indivíduos a deixarem de considerar o emprego estável como fonte de dignidade pessoal e coletiva (LEITE \& MELO, 2008; CAMPOS, 2003), sendo este, por conseguinte, avaliado como projeto de vida para sujeitos "acomodados" ou destituídos de ambição. Da mesma forma, faz parte da "receita" do "empreendedorismo" a responsabilização pessoal dos indivíduos por sua condição profissional e financeira, seja a situação de empregado ou desempregado, o sucesso ou o fracasso de sua atividade autônoma, ou mesmo a "sobrevivência" ou falência de seu empreendimento. A literatura do management, além disso, costuma apresentar o "empreendedorismo" como comportamento ou atitude particular que deve alcançar outras esferas sociais. Neste sentido, os indivíduos devem ser "empreendedores" (e esta pode ser uma obrigação moral) não apenas na esfera econômica, mas em sua vida como um todo (DIAS, 2008; LEITE et al., 2008).

Os meios de comunicação de massa, como citado anteriormente, têm sido estratégicos na difusão desses valores. É possível perceber, sobretudo nas três últimas décadas do século $\mathrm{XX}$, a proliferação de mídias particulares, cujo foco parece ser popularizar o mundo dos negócios e do management, difundindo certa lógica e pacotes gerenciais. Wood Jr. e Paula (2001) apontam para a tendência atual da mídia, particularmente a de negócios, de enfocar uma gama de assuntos gerais, cujo objetivo seria exaltar as façanhas grandiosas de gerentes-heróis e receitas para o "sucesso". A este fenômeno, os autores dão o nome de pop-management, isto é, versão "divertida" da cultura organizacional com forte apelo popular, estimulada pelo culto à excelência e pela difusão ideológica do "empreendedorismo".

Além da mídia voltada para o mundo dos negócios, Leite e Melo (2008), investem em análises de livros de auto-ajuda sobre carreiras, biografias de sucesso e sítios de negócios. As autoras percebem que as "histórias de sucesso" constantes nessas publicações realizam uma espécie de re-significação de papéis sociais, que se expressa, em geral, pela transformação, em termos discursivos, de trabalhadores precarizados em "empreendedores", destacados pela criação de algum produto "aceito no mercado". Além disso, as autoras verificam que o sujeito-alvo não é apenas o trabalhador de classe baixa ou o pequeno empresário.

A trajetória do grande capitalista do mercado financeiro ganha destaque, em revistas de negócios, por suas inovações e ousadia na gestão de sua empresa. Todas essas trajetórias, malgrado apresentem acidentes de percurso, são capazes de alterar, significativamente, a maneira como os leitores percebem a realidade. 
Criada pela Editora Abril em 1971, a Revista Exame tornou-se uma das principais referências da imprensa brasileira de negócios. Segundo Donadone (2000), o sucesso da revista deveu-se, dentre os muitos fatores, à consolidação do jornalismo econômico na década de 70 e à sua proposta editorial que tem privilegiado desde então a divulgação de estratégias de negócios. Segundo o mesmo autor, a opção de divulgar novas tecnologias e casos bem sucedidos de gestão, acabou atraindo um público ávido por informações sobre um novo contexto marcado por turbulências econômicas.

Vários autores dedicados à análise da "grande imprensa" brasileira encontram discursos essencialmente comprometidos com interesses da classe dominante, preocupada com a coesão social em torno da ordem política e econômica (CHAUÍ, 2006; FONSECA, 2004; FONSECA, 2003a; FONSECA, 2003b; ABRAMO, 2003; SILVA FILHO, 1998). Partindo-se deste pressuposto, e considerando que a revista Exame é agência da grande imprensa, é possível afirmar que suas narrativas não são indiferentes ao propósito de adesão de trabalhadores a novos valores, ou à nova "ética" do trabalho. Buscaremos verificar como os artigos sobre o "empreendedorismo" publicados nesta fonte podem trazer novos elementos a este debate.

\section{Implicações metodológicas da análise}

A investigação contou, em primeiro lugar, com levantamento e leitura de revistas brasileiras de negócios, mais especificamente Forbes Brasil, Você S.A. e Exame, e as revistas estrangeiras Forbes, Atualidad Económica e América Económica. A análise exploratória das fontes levou-nos a tomar a Exame como corpus de análise por ter perpetuado, em boa parte das edições, um conjunto de reportagens dedicadas à descrição de executivos(as) e proprietários(as) de empresas considerados(as) "empreendedores(as)" pelo discurso nativo e a fornecer sugestões aos leitores de como proceder para abrir ou gerir o seu próprio negócio.

As etapas seguintes foram: (1) estabelecimento de recorte temporal, abrangendo o período entre 1990 e 1999, o qual coincide com o início da implantação das políticas neoliberais pelos governos brasileiros e seu transcurso por uma década; (2) mapeamento de matérias sobre o tema em questão; (3) escolha das reportagens para análise; (4) exame dos conteúdos discursivos.

Foi necessário restringir o número de matérias, concentrando-nos naquelas cujas colunas ou títulos referiam-se diretamente ao termo "empreendedorismo" e derivações ("espírito empreendedor", "comportamento empreendedor" etc.). Assim, foram investigados 240 números da revista, acrescidos das edições especiais, e separadas 86 reportagens escolhidas segundo o critério mencionado. 
De 1990 a 1996, a revista mantinha uma coluna quinzenal chamada "Empreendedores", dentro da qual os jornalistas dedicavam-se a temas dirigidos aos aspirantes a empresários. Após 1996, esta coluna foi perdendo periodicidade, ficando o tema mais difuso em outras matérias, sobretudo, naquelas dedicadas a retratar perfis de executivos(as) e proprietários(as). De 1997 a 1999 encontramos um número menor de reportagens voltadas para o tema. Devido a estes fatores, a classificação dos artigos apresentada adiante será feita a partir de recorte heterodoxo do material-primário: de 1990 até 1996 foram separadas dez reportagens por ano de publicação, todas extraídas da coluna "Empreendedores". A partir de 1997, as reportagens que compõem a amostra constam de seções distintas distribuídas pela revista. Contamos com seis reportagens publicadas em 1997, cinco em 1998 e cinco em 1999.

Pretendemos, a seguir, reunir idéias que apareçam de forma invariável ou descontínua durante dez anos de publicação, em matérias escritas por diferentes autores, e sob a responsabilidade de diferentes editores, de tal forma que uma nova classificação, reunida num esforço de síntese, consiga inferir os princípios ideológicos da fonte. A análise, por conseguinte, tem como limite privilegiar um exame geral das narrativas ao invés de prováveis alterações de conteúdo ideológico ocorridas ao longo de tempo.

\section{"Empreendedorismo" como objeto: análise das reportagens}

Separamos as reportagens em seis grupos diferentes, classificados a partir de seus conteúdos e objetivos: "conjuntura econômica"; "aspectos culturais e históricos"; "dicas de gestão"; "oportunidades" (para quem quer abrir uma empresa); "o papel das boas idéias" (e como começar um negócio sem uma); "definições para empreendedor". A maioria das matérias, no entanto, poderia vincular-se a mais de uma categoria, posto que os assuntos se entrelaçam continuamente numa mesma narração. Este recurso analítico visa organizar, preliminarmente, o extenso número de textos da amostra para servir de base para inferências e generalizações. Assim, num segundo momento, buscamos avaliar o que as narrativas, que tratam de assuntos diversos, têm propriamente em comum.

\section{Conjuntura econômica}

Quatro matérias selecionadas ${ }^{3}$ consideram certos aspectos econômicos responsáveis pelo impulso dos indivíduos de se tornarem empresários.

3 "Os sonhos saem do papel" (05/07/1995), "Geração coca-cola" (20/11/1996), "Bem-vindos à vida como ela é" (27/03/1996), "A vida dos downsizaados" (08/05/1996). 
Um dos temas recorrentes diz respeito ao problema da falta de emprego que marca aquela conjuntura. Uma matéria ${ }^{4}$ aborda a abertura de empresas por um grupo de indivíduos atingidos pelo Plano de Demissão Voluntária do Banco do Brasil. Na narrativa, o autor exalta histórias de ex-funcionários que multiplicaram seus ganhos ao abrirem um pequeno negócio, e outros que ainda não haviam conseguido o sucesso esperado, mas que continuavam acreditando nesta alternativa. Outra reportagem ${ }^{5}$ apresenta uma série de situações enfrentadas por um conjunto de ex-funcionários e ex-executivos de grandes empresas que, por motivos diversos, deixaram os cargos para lançarem-se "de forma corajosa" no mundo dos negócios.

Ao mesmo tempo em que retratam a diminuição de postos de trabalho, jornalistas afirmam a necessidade de desenvolver nos jovens um "espírito empreendedor"6 que eliminaria a sua dependência de um mercado de trabalho em transformação. Por outro lado, a estabilidade econômica da época é ressaltada como incentivadora da abertura de firmas por executivos audazes que "não pensam duas vezes" diante do "desafio" de se tornarem patrões.

Deste modo, tanto a crise que leva ao desemprego como a estabilidade econômica são apresentadas como fenômenos que desafiam indivíduos a buscarem novas formas de sobrevivência, particularmente na atividade empresarial. Ainda que as reportagens apresentem as dificuldades dos sujeitos em lidar com o mundo dos negócios, este se revela associado à coragem, além de ser considerado mais virtuoso se comparado à função dos funcionários dependentes.

\section{Aspectos culturais e históricos}

Outras duas matérias ${ }^{7}$ apresentam aspectos sócio-culturais e históricos ora como responsáveis pelo caráter naturalmente "empreendedor" do brasileiro, ora por sua inércia. Numa reportagem ${ }^{8}$, em especial, o jornalista questiona por que os estadunidenses são mais "empreendedores" do que os brasileiros. A resposta seria porque, embora no Brasil haja o tino inventivo, haveria uma série de problemas intrínsecos à história do país, como, por exemplo, a estatização dos governos Getúlio Vargas (1882-1954) e Juscelino Kubitschek (19021976), o populismo de Estado, as utopias socialistas e o legado religioso, que teriam ocasionado uma espécie de comportamento típico do brasileiro que o levaria a perder grandes oportunidades de negócios. O indivíduo nacional,

\footnotetext{
4 "Bem-vindos à vida como ela é" (27/03/1996).

5 "A vida dos downsizaados" (08/05/1996).

6 "Geração coca-cola" (20/11/1996) e "Bem-vindos à vida como ela é" (27/03/1996).

7 "Os sonhos saem do papel" (05/07/1995) e "Por que os americanos são melhores que nós" (10/09/1997).

8 "Por que os americanos são melhores que nós" (10/09/1997).
} 
por exemplo, teria mais simpatia pelos desafortunados do que pelos bem-sucedidos, identificados como egoístas e espoliadores. Ao mesmo tempo, teria "horror atávico ao risco", e daria preferência pelos passos comedidos. Enquanto, por outro lado, "o protestantismo americano, associado à tradição política liberal daquele país, livra os Estados Unidos dessa tortuosidade"10. De forma inversa, outro jornalista conclui que com a nova unidade monetária (Real), "muitos outros [empreendedores] virão", pois que - transcrevendo a opinião de um consultor do SEBRAE - "o brasileiro sempre teve um forte espírito empreendedor, dispondo de muita coragem para abrir novos negócios numa época em que era preciso rever o planejamento estratégico a cada mês". ${ }^{11}$

Logo, dificuldade e facilidade de se implementar um novo negócio no país teriam relação com fatores estruturais da sociedade que incidiriam sobre aspectos cognitivos dos sujeitos, sendo que a cultura pode tanto justificar ações "empreendedoras" como caracterizar certo caráter indolente do nacional. Além disso, a abertura de uma firma é tratada como valor extremamente positivo, aliada novamente à idéia de coragem.

\section{Dicas de gestão}

Classificamos em "dicas de gestão" vinte e uma reportagens publicadas em todo o período da amostra, cujo propósito primeiro parece ser informar ao leitor aspectos bem gerais que envolvem a gestão de um negócio.

Parte das narrativas ${ }^{12}$ dá dicas para o empresário melhorar o relacionamento com os funcionários e motivá-los para o trabalho, além de sugestões voltadas para a contratação de bons empregados, posto que "o empreendedor não se pode dar ao luxo de ficar preso a um processo contínuo de contratações e demissões" ${ }^{\prime 13}$. Outras, incluídas nesta mesma categoria, focam a necessidade de realizar planejamentos. Em geral, avaliam a importância de se ter clareza em relação à idéia do negócio e propõem maneiras de como um "empreendedor" pode planejar o seu tempo ${ }^{14}$, como fazer um fluxo de caixa e um plano de negócios, levando-se em conta a estrutura operacional, concorrência e perfil do consumidor potencial ${ }^{15}$. Em uma matéria, em particular ${ }^{16}$, apresenta-se uma série de casos mal-sucedidos de gestão ocasionados por problemas com finanças,

\footnotetext{
9 Idem. p. 96.

${ }^{10}$ Idem. p. 96.

11 "Os sonhos saem do papel" (05/07/1995, p.115).

12 "Portas abertas: como iniciar o diálogo com seus funcionários" (3/02/1993), "Mãos à obra" (31/08/ 1994), "Aqui pode pichar" (02/03/1994), "Como avaliar pessoas" (01/02/1995).

13 "Como contratar bem sem amadorismo" (17/02/1993, p.103).

14 "O dia de 25 horas" (29/03/1995),

15 "Sintonia Fina nas Contas" (07/02/1990), "Confiar na intuição é um suicídio" (21/02/1990).

16 "O fracasso também dá lições" (01/05/1991).
} 
contabilidade e tributação. Alguns assuntos dizem respeito aos cuidados que um "empreendedor" deve tomar ao se decidir pela importação de produtos ou matérias-primas ${ }^{17}$. Em outros casos, são sugeridos procedimentos para quem quer abrir uma franquia, no que tange ao local onde abrir o negócio, para quem vender e como conseguir capital ${ }^{18}$. Também recorrente neste conjunto de textos são as vantagens e desvantagens de se manter uma loja em um shopping em relação às lojas instaladas nas ruas ${ }^{19}$. São abordadas também as especificidades das firmas do ramo de fast food étnico ${ }^{20}$; sugestões para "empreendedores" equilibrarem as retiradas de dinheiro com vistas a não abalarem a sua situação como pessoa jurídica ${ }^{21}$; procedimentos necessários para uma pessoa encontrar o negócio certo para o seu perfil profissional e pessoal ${ }^{22}$; dicas relativas à realização de seguros (sob medida para os micros, pequenos e médios empresários) ${ }^{23} \mathrm{e}$, por fim, medidas "modernas" para reestruturar as suas firmas, tais como kanban, just in time, downsizing ${ }^{24}$, formação de células de produção e diversificação ${ }^{25}$.

Em suma, os assuntos tratados nestas matérias parecem servir de exemplo para médios, pequenos e micro-empresários se esmerarem quando do início ou desenvolvimento de um negócio próprio. Desta feita, são apresentadas fórmulas de conduta cuja intenção, em princípio, parece ser levar o leitor empresário a contornar alguns obstáculos do mundo dos negócios ou enfrentá-los de forma mais adequada. Ao mesmo tempo, estas mesmas matérias consolidam valores particulares - como a idéia de eficiência e de motivação -, além de propagarem uma racionalidade empresarial baseada no planejamento e no controle, necessários para a eficácia de um empreendimento.

\footnotetext{
17 "Portas abertas aos bons negócios" (16/05/1990),

18 "Cinco perguntas para abrir uma franquia" (20/07/1994), "Virei empresário. O que faço agora?" (14/01/1998).

19 "A crise deixa a rua mais charmosa" (23/01/1991), "Os inquilinos estão em pé de guerra" (28/11/ 1990), "Vale a pena ter loja em shopping?" (02/07/1997)

20 "O sotaque entra no prato do dia" (05/08/1992).

21 "Melhor pobre que falido" (24/06/1992)

22 "Como cortar caminho para virar patrão" (30/10/1991), "Como abrir o negócio certo na hora certa" (03/03/1993).

23 "Seguro sob medida para os pequenos" (30/05/1990).

${ }^{24}$ Os termos Kanban, Just in time e Downsizing, o primeiro de origem japonesa e os dois últimos do inglês. são usados, de forma geral, como referência às inovações nas formas de produção implementadas pelas fábricas da Toyota, que foram adotadas e adaptadas a outros contextos produtivos por grandes indústrias em todo o mundo. Kanban é o nome dado ao registro, através de cartão, dos fluxos de produção. Just in time é o termo usado para referir-se ao sistema de produção por demanda, para o qual a matéria-prima ou o produto necessário para a fabricação chega à fábrica em quantidade exata e no momento certo, até que a empresa consiga alcançar o estoque zero. E, por fim, Downsizing significa, em inglês, diminuição de tamanho. "No contexto administrativo, significa, via de regra, que se está diminuindo ou enxugando estruturas organizacionais. Pode implicar demissão de pessoas ou reorganização do trabalho em que funções, níveis hierárquicos e mesmo unidades são eliminados. Representa uma estratégia que afeta o tamanho da força de trabalho, os custos e os processos de trabalho" (WETZEL, U. Histórias de Recomeço. Privatização e Downsizing. Ed. Maud: COPPEAD, Rio de Janeiro, 2000, p.13).

25 "Pequenos que agem como grandes" (15/04/1992).
} 


\section{Oportunidades}

Outro conjunto de matérias pretende, em meio a outras questões, apresentar ao leitor os ramos de atividades onde é possível encontrar maiores oportunidades de negócios. Encontramos vinte cinco textos jornalísticos ${ }^{26}$ que se inserem nesta categoria.

Podemos afirmar, em linhas gerais, que as matérias com esta particularidade tratam os temas a partir de histórias de pessoas que abriram empresas e foram bem ou mal sucedidas. Nelas, traduz-se, ao mesmo tempo, certa exaltação de indivíduos, cuja característica principal parece ser enxergarem oportunidades de negócios, ou seja, segundo o próprio discurso nativo, serem detentores de uma espécie de "olho esperto".

Os casos abordados têm como cenário uma gama de atividades empresarias, desde confecção de bonecos, setor de informática, exploração de pistas de Kart, firmas de entretenimento voltado para crianças e adolescentes, ramo de ecoturismo e de estacionamentos em grandes cidades, para citar alguns exemplos. Algumas reportagens selecionadas procuram informar ao leitor que pretende abrir um negócio sobre as chances oferecidas por empresas franqueadoras nacionais e multinacionais. Outras recomendam a terceirização como sendo um mercado em expansão.

Deparamo-nos também com reportagens que discorrem sobre as chances para indivíduos que têm "o vírus do empreendedor", mas não tem muito capital para abrir uma firma. Um jornalista ${ }^{27}$, por exemplo, apresenta cinco ramos de negócios em expansão - internet, painéis eletrônicos, mecânica de automóveis para carros com injeção eletrônica, serviços de análise jornalística para empresas e pet shops - que foram exploradas por empresários que contavam com menos de $\mathrm{R} \$ 100.000,00$ para investimentos iniciais. As oportunidades que aparecem para quem pretende abrir a sua própria firma numa economia em recessão é o tema de outra narrativa ${ }^{28}$,

26 "Chegou a hora dos pesos pesados" (21/03/1990), "Como ainda é verde o nosso vale" (04/04/1990), "A arte de faturar guardando carros" (07/08/1991), "Como aproveitar os tempos de crise" (26/06/ 1991), "De olho no apetite da garotada" (04/09/1991), "Como prosperar na brincadeira" (03/04/ 1991), "Quando todo o cuidado ainda é pouco" (15/05/1991), "As oportunidades que vêm de longe" (22/07/1992), "Itabira corre atrás do trem da história" (22/01/1992), "Esse é um negócio das Arábias, com certeza" (09/12/1992), "Onde estarão as boas oportunidades em 93" (20/01/1993), "Os homens que fazem a cabeça da moçada" (23/06/1993), "As oportunidades em serviços nota 10" (29/09/ 1993), "Onde estão as oportunidades de negócios" (01/09/1993), "As oportunidades que chegam de fora" (26/10/1994), "A ordem do dia é fazer CD-ROM" (28/09/1994), "Eles são como um novo Gepeto" (08/06/1994), "Tem que ser grande para entrar no time" (02/08/1995), "Sai a mulata e entra o boto-cor-de-rosa" (27/09/1995), "Em altíssima velocidade" (22/11/1995), "Bom e barato" (06/12/ 1995), "Ganhado dinheiro com Mouse Pads" (22/05/1996), "Rota do espaço" (05/06/1996), "Os vovôs entram na internet" (24/04/1996) e "Negócios da China no Brasil do Real" (09/10/1996).

27 "Bom e barato" (06/12/1995).

28 "Como aproveitar os tempos de crise" (26/06/1991). 
na qual se afirma que é justamente em situações de turbulência econômica que muita gente está disposta a negociar, baixar preços, facilitar pagamentos, ceder empréstimos, vender sua infra-estrutura a preços de liquidação.

Do mesmo modo que as narrativas que versam sobre formas de gestão, estas parecem abordar também questões práticas, só que relacionadas às informações sobre oportunidades de mercado para novos negócios. Além disso, parece importante destacar o fato de que estas matérias, em consonância, procuram apresentar ao leitor uma maneira própria de se observar um campo de atuação - o "mercado" - que, tratado como sujeito ou entidade abstrata, deve ser compreendido e desvendado. $\mathrm{O}$ "empreendedor" deve encontrar "nele" perspectivas, brechas, nichos para seu desempenho profissional, através de uma visão particular - vislumbrando, percebendo, intuindo, descobrindo possibilidades. Assim, busca-se uma espécie de aprimoramento da percepção dos sujeitos sobre o mercado, mas que se estende para uma percepção do mundo social que está à sua volta.

\section{As boas idéias (ou como começar um negócio sem uma boa idéia)}

No campo das ciências sociais aplicadas, alguns estudos têm afirmado a relação direta entre o "empreendedorismo" e o nascimento de uma idéia revolucionária capaz de alterar significativamente os rumos da economia de mercado. Na revista em análise, em contraste, encontramos textos que realizam tanto a consagração de empresários e executivos autores de grandes idéias, quanto a negação das invenções como condição imprescindível para um negócio ser bem sucedido. Neste segundo caso, os "empreendedores" não são necessariamente inventores, são indivíduos que enxergam oportunidades. Encontramos 10 matérias ${ }^{29}$ que se inserem nestes dois casos.

Algumas reportagens, que relacionam "empreendedorismo" e criatividade, acabam por exaltar indivíduos por sua capacidade criadora. Mas, por outro lado, afirmam a necessidade destes de terem também características de um empresário convencional, como, por exemplo, capacidade de elaborar um plano de negócios eficiente e persuasivo. Um conjunto de matérias narra histórias de alguns empresários que abriram empresas depois de desenvolverem grandes invenções, tais como calibrador de pneus, conversor de combustível de automóveis e o sterilair ${ }^{30}$. Da mesma forma,

\footnotetext{
29 "Quando o dinheiro não é tudo" (24/01/1990), "O primeiro tropeço pode ser a salvação" (04/08/ 1993), "O começo de quem conseguiu chegar lâ" (13/10/1993), "Um negócio na cabeça e uma idéia na mão" (08/12/1993), "Só faltava essa: um lava-rápido a seco" (14/09/1994), "Quem colocou o ovo em pé" (23/10/1996), "Do (quase) zero ao infinito" (08/10/1997), "Meu amigo capitalista" (19/11/ 1997), "Prêmio para quem faz diferença" (25/03/1998), "Investidores do bem" (06/10/1999).

${ }^{30}$ Aparelho destinado à esterilização de ambientes.
} 


\section{Empreendedorismo como ideologia: uma análise do enfoque da revista Exame ...}

revelam que há uma série de empresas que começaram suas atividades com muito pouco capital, mas com criatividade. Isto é, muita gente sem capital conseguiu "identificar oportunidades quase invisíveis, detectou um nicho novo ou mesmo explorou ramos tradicionais - com uma dose extraordinária de talento e disciplina". ${ }^{31}$

No revés, alguns jornalistas desconsideram a invenção como propulsora de um negócio bem sucedido. Alguns deles asseguram que pouco capital e atenção às necessidades dos consumidores são o suficiente para render um bom negócio. Um dos vários casos apresentados em uma das matérias é o de um empresário que fundou uma firma de serviços destinada a realizar e entregar compras de feira em domicílio. Em meio aos percalços iniciais, ele foi aprendendo os truques do negócio e aumentando a sua rentabilidade. Assim, a narrativa conclui que tanto vale uma nova idéia como uma antiga passada a limpo. Basta "acompanhar os movimentos da sociedade com os olhos atentos (...). [É] na percepção das necessidades criadas por mudanças políticas, sociais e econômicas que novos negócios acontecem". ${ }^{32}$

No mesmo sentido, outros jornalistas revelam o nome de firmas que, embora muito bem sucedidas, não iniciaram as suas trajetórias com invenções bombásticas. Os proprietários da Localiza, Método Engenharia, Springer, Tec Toy, Giovanna Baby e João Fortes Engenharia, por exemplo, começaram "pequenos, inseguros e cheios de dúvidas quanto ao futuro" ${ }^{33}$. De forma análoga, HP, Motorola, Honda, Disney e Sony, dentre outras empresas citadas, não surgiram, segundo o jornalista, a partir de uma grande invenção. Somente com o passar do tempo é que os sócios desenvolveram produtos que alavancaram o seu sucesso em âmbito mundial. Apresentando estes exemplos, as reportagens registram a importância de persistir: "esteja preparado para abortar uma idéia, mas nunca desista da empresa. Se uma idéia naufraga, tente outra". ${ }^{34}$

Assim, este conjunto de matérias acima pressupõe que ter uma boa idéia para iniciar um negócio não é privilégio de todos os indivíduos. No entanto, este não parece ser motivo para o leitor desistir de seus planos de "empreender". Observa-se no discurso, portanto, uma mensagem moral, que afirma que aquele que não possui o "espírito" do inventor, ou seja, que não nasceu com certas características "empreendedoras", deve vencer pelo uso da racionalidade e da perseverança.

\footnotetext{
31 "Do (quase) zero ao infinito" $(0 \overline{08 / 10 / 199} 7$, p.51)

32 "Quando o dinheiro não é tudo" (24/01/1990, p.85)

33 "O começo de quem conseguiu chegar lá" (13/10/1993, p.113)

34 "O primeiro tropeço pode ser a salvação" (04/08/1993, p.77)
} 


\section{Definições para "empreendedor"}

Durante a leitura dos artigos, encontramos pelo menos vinte e nove textos ${ }^{35}$ cujo objeto é, em meio a outras questões, a caracterização de empresários e executivos considerados "empreendedores". As características próprias de sujeitos consagrados pelo discurso ora se repetem, ora ganham significados diversos de acordo com os contextos discursivos.

Em uma matéria particular ${ }^{36}, o$ jornalista apresenta o perfil de quarenta empresários considerados, segundo o autor, verdadeiros mitos do capitalismo mundial e nacional. É possível perceber nela a exaltação de características vinculadas diretamente à inventividade, ousadia, caráter e força física dos retratados.

Um número expressivo de reportagens, diferentemente, refere-se aos herdeiros que, por questões contingenciais ou não, tiveram que assumir as empresas da família. Por deterem o que os autores chamam de um "feeling pessoal", caminharam na contramão das cartilhas de negócios e, em muitos casos, deixaram a prudência de lado, apostaram no talento e tiveram coragem para assumir desafios, rejuvenescendo, ampliando, ousando e recriando a empresa original. "Eles inventam soluções, recriam rotinas de trabalho, diversificam as linhas de produtos e, não raramente, enxergam brechas que ninguém antes havia percebido" 37 , informa uma das matérias.

Além destes aspectos, é possível perceber que a idéia de "sujeito empreendedor" ainda exibe outros conteúdos significantes: detentor de idéias brilhantes, motivado pelo desafio da competitividade e pelo desejo de vencer, polivalente, competente, dotado de visão estratégica, trabalhador incansável, alguém que vislumbra o futuro, idealizador, executor, cidadão do mundo, detentor de educação cosmopolita e de alto grau de instrução,

35 "Dores e prazeres de uma vida dupla" (07/03/1990), "Filho de peixe peixão é" (10/01/1990),

"A lei do salmão no escritório" (09/01/1991), "O patinho feio que virou cisne" (20/03/1991), "Quando o negócio é ter vida dupla" (19/02/1992), "A prova dos nove de quem quer voar" (01/ 04/1992), "O berço não é o bastante" (11/11/1992), "Nunca é tarde para começar de novo" (16/09/1992), "O lance brilhante de um jogador nem tanto" (30/03/1994), "Quando o sangue não impede o sucesso" (02/02/1994), "Um dream team à napolitana. No Rio" (06/07/1994), "Bits e Bytes sem mistério" (15/02/1995), "Luxo na praia é com ele mesmo" (13/09/1995), "Como ficar sócio de uma multinacional" (12/04/1995), "Lucros sob pressão" (14/08/1996), "O poder do fracasso" (31/07/1996), "Dupla Jornada" (07/05/ 1997), "Milionários" (27/08/ 1997), "Podem me chamar de cerveja" (26/08/1998), "Viagem ao Planeta Helder" (04/11/ 1998). "Ganhar dinheiro é tão simples..." (25/03/1998), "O sexo frágil manda no Vale do Silício" (29/01/1998), "A receita era da vovó" (22/04/1998), "Os maiores empreendedores do Brasil: Os homens que construíram o capitalismo brasileiro neste século" (15/12/1999), "Nova Economia" (25/08/1999), "Negócio Próprio" (17/11/1999), "Os 20 maiores empreendedores do mundo" (15/12/1999).

36"Os 20 maiores empreendedores do mundo" (15/12/1999) e "Os maiores empreendedores do Brasil: Os homens que construíram o capitalismo brasileiro neste século" (15/12/1999).

37 "Filho de peixe peixão é" (10/01/1990, p.82). 
além de apresentar certa hipermetropia que faz este sujeito enxergar para além do campo de visão dos "não-empreendedores". ${ }^{38}$

Também podemos encontrar entre as definições sujeito com vocação incontrolável para "empreender" ou para tornar-se patrão. Neste caso, a acepção de "empreendedor" está vinculada à idéia de personalidade como unívoca à natureza humana, diferente, portanto, da explicação que aproxima características pessoais de produções sócio-culturais. Assim, de acordo com uma matéria ${ }^{39}$,"nem todos os profissionais ou executivos estão habilitados a dar seu grito de independência. A dura realidade é que muitos jamais devem se aventurar a criar seus negócios. São ótimos quando comandados, mas serão péssimos comandantes". 40

No entanto, esta perspectiva é exceção diante da maioria dos artigos que incorpora na definição de empreendedor os sujeitos "não vocacionados" ou aqueles que não são "empreendedores" natos, mas que conseguem alcançar o sucesso quando seguem determinadas receitas de conduta. Segundo o ponto de vista de um jornalista, por exemplo,

Para alguns empreendedores começar um negócio parece parte do destino. São empreendedores que têm a garra e a vontade de vencer no sangue. Nada, nenhum problema é capaz de demovê-los da meta de erguer uma empresa. A grande maioria, no entanto, não conta com esse fogo interior, e abrir um negócio se torna uma idéia que amadurece com o tempo". ${ }^{1}$

Este segundo tipo de sujeito "empreendedor", segundo a mesma matéria, precisa usar todo tempo a racionalidade tanto para planejar o seu negócio como para perguntar-se se realmente gosta do que faz. Embora pareça estar em desvantagem em relação aos "empreendedores por natureza", ele teria personalidade, persistência, autoconfiança e moderação na tomada de decisões.

\footnotetext{
38 "Dores e prazeres de uma vida dupla" (07/03/1990), "Filho de peixe peixão é" (10/01/1990), "A lei do salmão no escritório" (09/01/1991), "O patinho feio que virou cisne" (20/03/1991), "Quando o negócio é ter vida dupla" (19/02/1992), "A prova dos nove de quem quer voar" (01/04/1992), "O berço nâo é o bastante" (11/11/1992), "Nunca é tarde para começar de novo" (16/09/1992), "O lance brilhante de um jogador nem tanto" (30/03/1994), "Quando o sangue não impede o sucesso" (02/02/1994), "Um dream team à napolitana. No Rio" (06/07/1994), "Bits e Bytes sem mistério" (15/02/1995), "Luxo na praia é com ele mesmo" (13/09/1995), "Como ficar sócio de uma multinacional" (12/04/1995), "Lucros sob pressão" (14/08/1996), "O poder do fracasso" (31/07/1996), "Dupla Jornada" (07/05/ 1997), "Milionários" (27/08/1997), "Podem me chamar de cerveja" (26/08/1998), "Viagem ao Planeta Helder" (04/11/ 1998), "Ganhar dinbeiro é tão simples..." (25/03/1998), "O sexo frágil manda no Vale do Silício" (29/0I/ 1998), "A receita era da vovó" (22/04/1998), "Os maiores empreendedores do Brasil: Os homens que construíram o capitalismo brasileiro neste século" (15/12/1999), "Nova Economia" (25/08/1999), "Negócio Próprio" (17/11/1999), "Os 20 maiores empreendedores do mundo" (15/12/1999).

39 "Negócio Próprio" (17/11/1999)

40 (p. 184)

41 "A prova dos nove de quem quer voar" (01/04/1992, p.76).
} 
E se ele gosta do que faz, irá "querer sempre mais e mais, enquanto as tempestades do dia-a-dia deixam de ser dor de cabeça para ser simples desafio". ${ }^{42}$

Portanto, as narrativas afirmam, em geral, um conjunto de características distintas, naturais ou não, que definem os chamados "empreendedores". Ainda que muitas vezes instintivos e sensíveis, com capacidade de 'enxergar' mais do que os outros - ou seja, tendo características incompreensíveis para qualquer tentativa de explicação objetiva - eles podem ter capacidade de planejar e de trabalhar, além de deter alto grau de instrução, aspectos estes já relacionados à dimensão sócio-cultural, e adquiridos no contexto das relações sociais.

\section{Conclusão: seja empresário, "custe o que custar".}

Nosso objetivo, como apontado inicialmente, foi compreender como a revista Exame apresenta, durante 10 anos de publicação, definições particulares para o "empreendedorismo", a fim de realizar, posteriormente, uma síntese de seu conteúdo discursivo. O propósito final é desvendar a ideologia produzida por esta mídia a partir desta idéia particular.

A classificação das matérias por temáticas já assinalou, inicialmente, parte dos resultados encontrados. Em suma, os jornalistas da Exame: 1) afirmam a existência de um ambiente econômico naturalmente propício para os "empreendedores", deixando de problematizar o próprio contexto que tomam como base; 2) apresentam continuamente a abertura de uma firma como algo a ser perseguido pelos sujeitos, dando a esta ação um status extremamente positivo e diferenciado em relação ao emprego assalariado; 3 ) dão dicas de oportunidades e sugestões de como lidar com o mundo dos negócios, difundindo, assim, práticas sociais, racionalidade de tipo particular e nova ética do trabalho considerada indispensável ao novo contexto econômico; 4) afirmam que a possibilidade de "se tornar patrão" é viável a todos os indivíduos, tanto para os inventivos quanto àqueles que não detém boas idéias, incluindo empregados e desempregados, jovens e veteranos, pessoas com muito ou pouco capital, ampliando, assim, o campo de alcance do "empreendedorismo".

Portanto, é possível perceber que o objeto das narrativas é a pequena unidade produtiva, mais precisamente o ethos de pequenos empresários ou de aspirantes a empresários - que "devem começar pequenos para se tornarem grandes". Desta forma, a mídia se ajusta aos objetivos da nova organização da produção capitalista, que, tornada flexível, exige um número maior de pequenos negócios dispostos horizontalmente na órbita da grande indústria. Sua preocupação centrase, então, na ampliação, "sobrevivência" e qualidade dos serviços oferecidos pelas pequenas, cuja eficiência auxilia sobremaneira o funcionamento das grandes.

\footnotetext{
${ }^{42}$ Idem. p. 78.
} 
É possível observar também que o termo "empreendedorismo", vinculado às pequenas empresas, presta-se a sentidos múltiplos nas diferentes narrativas. Em alguns casos, é simplesmente sinônimo de abertura de um negócio. Isto é verdadeiro, sobretudo, para aquelas matérias nas quais os autores dedicam-se a ensinar a abrir e gerir uma empresa. Em outros, o termo identifica-se com a figura do "empreendedor", que ora é um sujeito com características particulares natas, ora um técnico que usa a racionalidade para alcançar objetivos - quando não possui os dois atributos concomitantemente. Quando focam o sujeito que, de seu ponto de vista, não nasceu "empreendedor", os jornalistas têm o cuidado de afirmar que isto não seria um empecilho para ele deixar de "empreender". Pelo contrário, este sujeito acaba sendo exaltado pelo o que os autores consideram a superação de inaptidões através do aprimoramento e capacitação para o mundo dos negócios. Em geral, este significado dado ao termo aparece nas matérias que descrevem e exaltam personalidades, e naquelas que ilustram sugestões para abertura ou gestão de firmas com experiências particulares de empresários. Por fím, há, também, um número significativo de narrativas que trata o termo como sendo um viés cognitivo do sujeito. Neste caso, ele é representado como sinônimo de visão de mundo, como uma forma de vislumbrar oportunidades e enxergar além do alcance do campo de visão dos "não-empreendedores". Assim sendo, o sujeito "empreendedor" é aquele avaliado como visionário, como alguém que tem "idéias brilhantes", que tem um "olho esperto" e sensibilidade para entender o que está a sua volta. Encontramos estes juízos em matérias que expressam dicas e oportunidades de negócios.

Dentre estes aspectos citados, aparece em destaque a convergência de grande parte dos jornalistas com relação à idéia de que, mesmo que o talento para empreender não seja universal, todos podem aprimorar competências para os negócios. Se alguém pretende abrir uma firma, pode aperfeiçoar o olhar para vislumbrar oportunidades; pode treinar habilidades para administrar; pode aprender com os erros; se não tem uma boa idéia, pode persistir; se não tem capital, deve buscar negócios mais baratos; se não têm intuição, deve planejar; se o período é de crise econômica, deve aproveitar as oportunidades que vêm a reboque dela. Logo, as idéias em torno do discurso do "empreendedorismo" sugerem que todos os indivíduos podem se tornar empresários, basta que sigam certos procedimentos e que tenham ânimo para perseverar. Em síntese, tratase de defender o empresariamento custe o que custar.

Desta feita, deparamo-nos com um discurso ideológico pautado na perspectiva de individuação, que se apresenta, sobretudo, na idéia do "empoderamento" individual, ou seja, na idéia de que o indivíduo é dotado de poder capaz de levá-lo a realizar tudo o que pretende. Ele tudo pode, basta vontade e persistência. Isto não significa que a revista tenha deixado de informar ao leitor aspectos relacionados a leis, burocracias ou impedimentos próprios do ambiente de negócios. 
Contudo, na maior parte das vezes, os percalços são tratados a partir de dramas ou estratégias individuais de enfrentamento, considerados centrais em detrimento de aspectos contextuais mais gerais. Características particulares dos sujeitos são reconhecidas como adequadas ou inadequadas, mas todas são adaptáveis aos "novos tempos", cuja acepção última é a inapelável imutabilidade. Ao eximir-se da problematização do contexto político-econômico, tratando-o como inflexível, a revista defende a sua perenidade.

Partindo-se do pressuposto de que o discurso ideológico, como exposto, guarda certa substância real, porque consegue fazer com que os receptores se identifiquem com o que é transmitido, mas que também apresenta certa substância falsa, uma vez que não expõe as contradições implicadas no próprio discurso, observamos que as matérias analisadas, em seu conjunto, acertam quando admitem que alguns empresários são mais bem sucedidos do que outros e que é possível, em qualquer campo profissional e da vida, perseverar e contornar obstáculos. Esta idéia deve ser familiar para os leitores que, certamente, conhecem histórias semelhantes àquelas apresentadas. Mas, ao mesmo tempo, ao ajuizar que sucesso e fracasso são obra exclusiva do preparo ou despreparo dos sujeitos para o mundo dos negócios ou de sua sensibilidade para perceber oportunidades, as narrativas deixam de lado aspectos relativos à própria dinâmica do sistema capitalista que, dentre outros fatores, não dispõem de possibilidades estruturais para todos os indivíduos se tornarem homens de negócios. Ao mesmo tempo, a sobrevivência de um pequeno negócio não depende exclusivamente de uma gestão eficiente, mas do desempenho das grandes indústrias às quais está ligado direta ou indiretamente.

Por fim, a idéia do "empreendedorismo" - que advém de uma necessidade real de produção de emprego e renda - acaba tendo como função a criação de subsídios para a construção do ambiente cultural e ideológico apropriado a uma nova Era do Capital. Os instrumentos discursivos da revista estão pautados, em geral, na afirmação da individualização e do mérito e de propostas concretas de formas de ser, ver e agir numa década marcada pela reestruturação no campo da produção e da hegemonia. As propostas e procedimentos particulares parecem servir como canalizadores de um conjunto de idéias capazes de consolidar certa visão de mundo, cujo alicerce encontra-se numa lógica gerencial e empresarial a ser apreendida por todos os indivíduos.

\section{Referências bibliográficas}

ABRAMO, Perseu. Padrões de manipulação na grande imprensa. São Paulo: Editora Fundação Perseu Abramo, 2003. 
ALVES, G. Dimensões da reestruturação produtiva. Ensaios de Sociologia do Trabalho. Ed. Praxis, Londrina; Canal 6, Bauru, 2007.

ALVES, G. Trabalho e sindicalismo no Brasil: um balanço crítico da "década neoliberal” (1990-2000). Revista de Sociologia e Política, Curitiba, 19, p. 71-94, nov. 2002.

ANTUNES, R. Adeus ao trabalho? (ensaio sobre as metamorfoses e a centralidade do mundo do trabalho). Ed. Cortez, São Paulo, 1995.

ANTUNES, R. As Novas formas de acumulação de capital e as formas contemporâneas do estranhamento (alienação). Caderno CRH, v.37, 2001, pp. 23-45.

ANTUNES, R. Os Sentidos do trabalho: ensaio sobre a afirmação e negação do trabalho. Ed. Boitempo, São Paulo, 2003.

BERNARDO, M. H. Trabalho duro, Discurso flexível: uma análise das contradições do toyotismo a partir da vivência dos trabalhadores. Expressão Popular, São Paulo, 2009.

CAMPOS, M. de S. A Empresa como vocação: O SEBRAE e o empreendedorismo na cultura da informalidade como problema público. 2003. Tese (Doutorado em Sociologia). Curso de Pós Graduação em Sociologia e Ciência Política, Instituto Universitário de Pesquisas do Rio de Janeiro, IUPERJ/UCAM, Rio de Janeiro, RJ.

CARDOSO, A. M. Flexibilidade, empregabilidade e a ortodoxia neoliberal. In: A Década Neoliberal e a Crise dos Sindicatos no Brasil. São Paulo: Boitempo, 2003.

CHAUÍ, M. Cultura e democracia. Ed. Cortez, São Paulo, 2000.

DIAS, V. T. Produzindo o Eu S.A.: análise de artigos sobre a temática do "empreendedorismo" apresentados nos últimos três encontros da Associação Nacional de Pós-Graduação e Pesquisa em Administração - ENANPAD. In: $1^{\circ}$ Colóquio Hegemonia e Contra-Hegemonia. UFBA, Salvador, Bahia, 2008 (no prelo).

DONADONE, J. C. imprensa de negócios, dinâmica social e os gurus gerenciais. in: Encontro de estudos organizacionais - ENEO. Org. Associação Nacional de Pesquisa em Administração - ANPAD, 2000.

EAGLETON, T. Ideologia. Ed. da Universidade Estadual Paulista: Ed. Boitempo, São Paulo, 1997.

FONSECA, F. O conservadorismo patronal da grande imprensa brasileira. Opinião Pública, v. IX, nº 2, p. 73-92, 2003a. 
FONSECA, F. A grande imprensa e a constituição da agenda ultraliberal na "Nova República". Estudos Históricos, Mídia, n.31, 2003/b

FONSECA, F. Mídia e democracia: falsas confluências. Revista de Sociologia e Política. Curitiba, 22, p.13-24, jun. 2004.

GRAMSCI, A. Americanismo e fordismo. In: Cadernos do Cárcere, volume VI, 2001.

GRÜN, R. Em busca da nova pequena burguesia brasileira. In: Dados, vol. 43, $\mathrm{n}^{\circ} 2$, pp.345-372, 2000.

HARVEY, D. A condição pós-moderna. Ed. Loyola, São Paulo, 1992.

HOBSBAWN, E. A era dos extremos: o breve século XX - 1914 -1991. Cia das Letras, São Paulo, 1995.

JAMESON, F. Postmodernism or the cultural logic of late capitalism. New Left Review, 146, pp. 53-92, 1984.

LEITE, E. da S.; MELO, N. M. Uma nova noção de empresário: a naturalização do "empreendedor". In: Revista de Sociologia e Política. V. 16, n. 31, p. 35-47, Nov. 2008.

MACHADO DA SILVA, L. A. Da informalidade à empregabilidade (reorganizando a dominação no mundo do trabalho). Caderno CRH, v.37, p. 81-109, 2001.

NEVES, M. Reestruturação Produtiva, qualificação e relações de gênero. In: ROCHA, M. I. B. da. (org.). Trabalho e Gênero: mudanças, permanências e desafios. Ed. 34, São Paulo, 2000.

OFFE, C. Capitalismo desorganizado. São Paulo, Ed. Brasiliense, 1995.

ORGANISTA, J. H. C. O debate sobre a centralidade do trabalho. Ed. Expressão Popular, São Paulo, 2006.

SILVA, D. S. B. da. A categoria trabalho: centralidade ontológica e exploração capitalista. Dissertação de Mestrado. Escola de Serviço Social, UFRJ, Rio de Janeiro, 2008.

SILVA FILHO, E. J. da. De Sarney a FHC: a atuação partidária da imprensa na construção do neoliberalismo. Textos de Comunicação e Cultura, 39, pp. 131- 146, dez 1998.

WOOD JR., T. \& PAULA, A. P. P. de. Pop-management. XXV ENANPAD, Campinas, 2001, In: Anais... 